\title{
Propriedades físicas das sementes de pinhão-manso ao longo da secagem em diferentes temperaturas
}

\section{Physical properties of jatropha seeds during drying in differents temperature}

\author{
Valdiney Cambuy Siqueira ${ }^{1 *}$; Osvaldo Resende ${ }^{2}$; Tarcísio Honório Chaves ${ }^{3}$
}

Resumo

\begin{abstract}
Diante do destaque do pinhão-manso (Jatropha curcas L.) no cenário nacional e internacional e da importância do conhecimento das suas propriedades físicas para a contribuição no desenvolvimento de maquinários que auxiliem no processamento pós-colheita das sementes dessa cultura, objetivou-se com o presente trabalho determinar a porosidade intergranular e as massas específicas aparente e unitária das sementes de pinhão-manso submetidas à secagem em diferentes temperaturas do ar. $\mathrm{O}$ experimento foi desenvolvido no Instituto Federal Goiano - Câmpus Rio Verde, utilizando-se sementes de pinhãomanso, que foram submetidas à secagem em estufa com circulação de ar forçada. O experimento foi montado em delineamento inteiramente casualizado, em esquema fatorial $(5 \times 7)$, tendo como fatores as diferentes temperaturas $\left(45,60,75,90\right.$ e $\left.105^{\circ} \mathrm{C}\right)$ e os teores de água $(33,33 ; 28,56 ; 25,37 ; 21,26 ; 17,36$; 13,04 e 9,09 (\% b.u.)), previamente estabelecidos. Verificou-se que a temperatura do ar de secagem e o teor de água das sementes exerceram influência na massa específica aparente e na porosidade das sementes de pinhão-manso. Já a massa específica unitária é influenciada apenas pelo teor de água das sementes. A redução do teor de água causa decréscimo na porosidade e nas massas específicas aparente e unitária das sementes de pinhão-manso e não é possível identificar um comportamento diferenciado em relação as temperaturas utilizadas.
\end{abstract}

Palavras-chave: Jatropha curcas L., pós-colheita, teor de água, oleaginosa

\begin{abstract}
Given the prominence of jatropha (Jatropha curcas L.) in the national and international importance of knowledge of their physical properties contribution to the development for machinery to assist in post-harvest processing of this crop seeds, the objective of the work was to determine the porosity and the bulk density and true density of jatropha seeds subjected to different drying air conditions. The experiment was conducted at the Instituto Federal Goiano - Câmpus Rio Verde, using jatropha seeds, that were subjected to drying in an oven with forced air circulation. The experiment was a completely randomized design in a factorial design $(5 \times 7)$ having factors like the different temperatures $(45,60$, 75,90 and $105^{\circ} \mathrm{C}$ ) and moisture content $(33.33 ; 28.56 ; 25.37 ; 21.26,17.36,13.04$ and 9.09 (\% w.b.)), previously established. It was found that the temperature of the drying air and the seeds moisture content influenced the bulk density and porosity of the seeds of jatropha. Since the true density is influenced only by the seeds moisture content. The reduction moisture content decrease of the porosity and in the bulk density and true density of jatropha seeds and it is not possible to identify a distinct behavior regarding temperatures used.
\end{abstract}

Key words: Jatropha curcas L., post-harvest, moisture content, oilseed

\footnotetext{
${ }^{1}$ Eng $^{\circ}$ Agr $^{\circ}$., Doutorando em Engenharia Agrícola, Universidade Federal de Lavras, UFLA, Lavras, MG. E-mail: vcambuy@ yahoo.com

2 Eng $^{\circ}$ Agrícola, Prof. Dr., Instituto Federal de Educação, Ciência e Tecnologia Goiano, Campus Rio Verde, GO. E-mail: osvresende@yahoo.com.br

${ }^{3}$ Discente em Agronomia, Instituto Federal de Educação, Ciência e Tecnologia Goiano, Campus Rio Verde, GO. Bolsista PIBIC/ CNPq. E-mail: tarcisio.chaves@hotmail.com

* Autor para correspondência
} 


\section{Introdução}

A crescente preocupação mundial com o meio ambiente, juntamente com a busca por fontes de energia renováveis, coloca o biodiesel no centro das atenções e interesses. Diversos países, inclusive o Brasil, buscam o desenvolvimento tecnológico para a produção deste biocombustível, tanto em nível agronômico como industrial (ABDALLA et al., 2008).

Dentre as plantas que apresentam potencial para a produção de biodiesel está o pinhão-manso (Jatropha curcas L.). Segundo Arruda et al. (2004), o pinhão-manso é uma espécie oleaginosa que, por suas potencialidades, vem sendo considerada economicamente importante e tem como característica principal a resistência à seca, além da produção de óleo com boa viscosidade e estabilidade à oxidação. Souza et al. (2009), observaram um teor

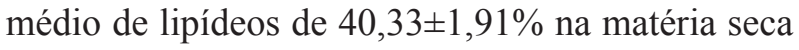
de sementes de pinhão-manso. Aliado a isso o óleo não é comestível e, portanto, não concorre com a alimentação humana (SATURNINO et al., 2005).

A maior parte do cultivo do pinhão-manso ainda é realizada em pequenas lavouras, onde os processos de colheita, secagem e armazenamento são feitos com reduzidos recursos tecnológicos. No entanto, com o advento do biodiesel, novas tecnologias deverão ser adotadas para atender as necessidades de uma produção em larga escala (SANTOS et al., 2009). Segundo Goneli et al. (2011), informações a respeito do tamanho, volume, porosidade e massa específica dos produtos agrícolas, são consideradas de grande importância para estudos que envolvem transferência de calor e massa e movimentação de ar em massas granulares. Sendo assim, para o desenvolvimento dos maquinários utilizados nas etapas de colheita e pós-colheita é de fundamental importância a determinação e o conhecimento do comportamento das propriedades físicas das sementes de pinhão-manso.

A redução do teor de água das sementes influencia diretamente suas propriedades físicas durante o processo de secagem, além de provocar o encolhimento dos mesmos (RESENDE et al., 2005). Cada produto apresenta características particulares de geometria e composição química, fazendo com que estes se comportem de forma diferente durante 0 processo de secagem. Logo, informações teóricas a respeito desta singularidade são de suma importância para auxiliar no desenvolvimento de equipamentos e adaptações daqueles já existentes, visando obter maior rendimento nesta etapa fundamental que é a fase de pós-colheita.

Segundo Silva (2008), a porosidade está associada à resistência que a camada de produtos oferece à movimentação do ar, sendo largamente utilizada nos projetos de equipamentos para secagem e armazenamento de grãos e sementes. É necessário se conhecer o volume de ar no interior de um silo, pois tal informação é fundamental para os cálculos da concentração de fumigantes ou da quantidade de ar necessária para a completa troca de ar nesse recipiente.

A aplicação do conceito de massa específica aparente é importante para a comercialização, dimensionamento de silos, secadores, depósitos e sistemas de transportes, podendo também ser utilizado para determinar teores de água, danos causados por insetos, bem como a deterioração fúngica nos produtos armazenados (SILVA, 2008).

Realizou-se o presente trabalho com o objetivo de avaliar a porosidade intergranular e as massas específicas aparente e unitária das sementes de pinhão-manso submetidos à secagem em diferentes temperaturas.

\section{Material e Métodos}

O experimento foi desenvolvido no Laboratório de Pós-colheita de Produtos Vegetais do Instituto Federal de Educação, Ciência e Tecnologia Goiano - Câmpus Rio Verde (IF Goiano - Câmpus Rio Verde). O experimento foi montado em delineamento inteiramente casualizado, em esquema fatorial $(5 \mathrm{x}$ 
7), tendo como fatores as diferentes temperaturas $\left(45,60,75,90\right.$ e $\left.105^{\circ} \mathrm{C}\right)$ e os teores de água $(33,33$; 28,$56 ; 25,37 ; 21,26 ; 17,36 ; 13,04$ e 9,09 (\% b.u.)), previamente estabelecidos. Utilizaram-se sementes de pinhão-manso, com teor de água inicial de 33,33 (\% b.u.), sendo submetidos à secagem em estufa com ventilação de ar forçada nas cinco temperaturas e umidades relativas de 15,$64 ; 7,42 ; 4,00 ; 1,78$ e $1,25 \%$, respectivamente, até atingirem o teor de água (Ta) de 9,09 $\pm 0,3$ (\% b.u.) determinado em estufa a $105 \pm 1{ }^{\circ} \mathrm{C}$, durante 24 horas, em três repetições (BRASIL 2009). A temperatura do ar de secagem foi monitorada por meio de um termômetro instalado no interior do secador. Sendo a umidade relativa obtida durante a secagem por meio dos princípios básicos de psicrometria utilizando-se o programa computacional GRAPSI (MELO; LOPES; CORRÊA, 2004). A secagem das sementes foi realizada em camada fina $(2,5$ cm aproximadamente), utilizando-se bandeja de alumínio contendo $500 \mathrm{~g}$ do produto, em três repetições.

A redução do teor de água, ao longo da secagem, foi acompanhada pelo método gravimétrico (perda de massa), por meio de uma balança analítica com resolução de $0,01 \mathrm{~g}$, conhecendo-se o teor de água inicial do produto, até atingir o teor de água desejado.

A massa específica aparente das sementes de pinhão-manso, expressa em $\mathrm{kg} \mathrm{m}^{-3}$, foi obtida durante a secagem utilizando-se uma balança eletrônica com resolução de $0,001 \mathrm{~g}$, e um recipiente com capacidade de $0,252 \mathrm{~L}$, em três repetições para cada teor de água.

A massa específica unitária das sementes, expressa em $\mathrm{kg} \mathrm{m}^{-3}$, foi determinada por meio da relação entre a massa de uma semente e o volume ocupado pela mesma. A obtenção do volume de uma semente foi realizada por meio da Equação 1, proposta por Mohsenin (1986). A determinação dos eixos ortogonais (comprimento, largura e espessura) para o cálculo de volume das sementes durante a secagem foi realizada com o auxílio de um paquímetro digital com resolução de $0,01 \mathrm{~mm}$, quando os mesmos se encontravam com os teores de água de: 33,$33 ; 28,56 ; 25,37 ; 21,26 ; 17,36 ; 13,04$ e 9,09 (\% b.u.), aproximadamente.

$$
\mathrm{V}_{\mathrm{s}}=\frac{\pi \cdot \mathrm{a} \cdot \mathrm{b} \cdot \mathrm{c}}{6}
$$

em que,

a: comprimento da semente, $\mathrm{mm}$;

b: largura da semente, $\mathrm{mm}$;

c: espessura da semente, $\mathrm{mm}$.

As dimensões características dos eixos ortogonais das sementes de pinhão-manso, foram determinadas conforme ilustrado na Figura 1.

Figura 1. Ilustração da determinação das dimensões características das sementes de pinhão-manso, considerado esferoide, (a) comprimento; (b) largura e (c) espessura.

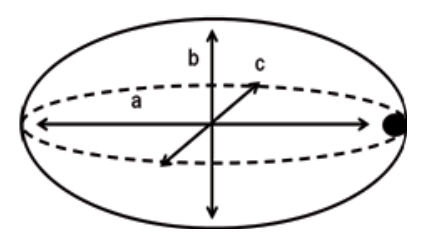

Fonte: Elaboração dos autores.

A porosidade das sementes de pinhão-manso foi calculada indiretamente por meio da expressão descrita por Mohsenin (1986):

$$
\varepsilon=\left[1-\left(\frac{\rho_{a}}{\rho_{u}}\right)\right] \cdot 100
$$

em que:

$\varepsilon=$ porosidade, $\%$;

$\rho_{a}=$ massa específica aparente, $\mathrm{kg} \mathrm{m}^{-3}$;

$\rho_{u}=$ massa específica unitária, $\mathrm{kg} \mathrm{m}^{-3}$. 
Os dados foram analisados por meio de análise de variância e regressão, sendo os modelos selecionados de acordo com o coeficiente de determinação e pela significância da equação pelo teste F, com o auxílio do programa aplicativo SISVAR 5.3, segundo Ferreira (2008).

\section{Resultados e Discussão}

Na Figura 2 estão apresentados os valores médios do teor de água das sementes de pinhão-manso submetidos a diferentes condições de secagem. Verifica-se na Figura 2, que o tempo necessário para que as sementes de pinhão-manso atingissem o teor de água experimental de 9,09 $\pm 0,3$ ( $\%$ b.u.), foi de 1,$26 ; 1,79 ; 2,60 ; 3,90$ e $7,11 \mathrm{~h}$ para as temperaturas de secagem de $105,90,75,60$ e $45^{\circ} \mathrm{C}$, respectivamente. Logo, o aumento da temperatura promoveu a redução no tempo de secagem das sementes de pinhão-manso, evidenciando o aumento da taxa de secagem, fato observado por diversos pesquisadores para inúmeros produtos agrícolas (LAHSASNI et al., 2004; MOHAPATRA; RAO, 2005; RESENDE et al., 2008a; SIRISOMBOON; KITCHAIYA, 2009; ULLMANN et al., 2010; SIQUEIRA; RESENDE; CHAVES, 2012a).

Figura 2. Valores médios dos teores de água das sementes de pinhão-manso ao longo do tempo de secagem em diferentes temperaturas.

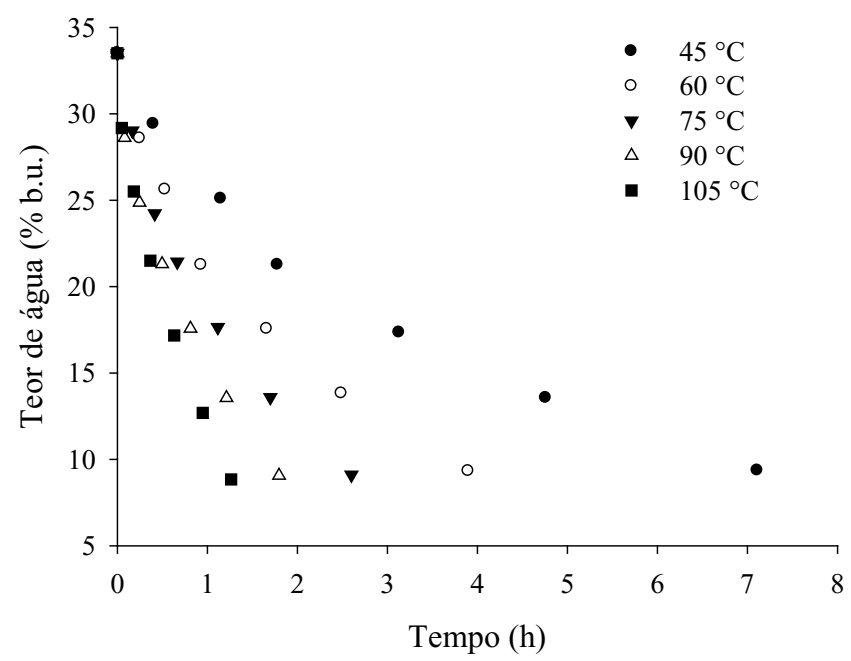

Fonte: Elaboração dos autores.

Ainda na Figura 2, observa-se que com o passar do tempo a redução do teor de água ocorre mais lentamente, uma vez que, o tempo necessário para remover a mesma quantidade de água é maior. Segundo Resende et al. (2009), com o decorrer do processo de secagem a taxa de redução de água diminui, pois a água se encontra fortemente ligada, necessitando de maior energia para a sua evaporação. Vale salientar que a ligação da água com a matéria seca do produto se torna mais forte à medida que a quantidade de água presente no grão diminui.

Verifica-se que, a temperatura do ar de secagem e o teor de água das sementes exerceram influência na massa específica aparente e na porosidade das sementes de pinhão-manso (Tabela 1). Já a massa específica unitária é influenciada apenas pelo teor de água das sementes. Sendo que a interação entre os fatores não promove alterações nas variáveis respostas analisadas. 
Tabela 1. Resumo da análise de variância para as massas específicas aparente e unitária e porosidade das sementes de pinhão-manso submetidos a diferentes condições de secagem.

\begin{tabular}{ccc}
\hline & Massa específica aparente & \\
\hline Fontes de variação & Quadrado médio & Coeficiente de variação (\%) \\
\hline Temperatura & $372,28^{*}$ & 1,63 \\
Teor de água & $9528,36^{*}$ & $77,76^{\text {ns }}$ \\
Temperatura x Teor de água & Massa específica unitária & \\
\hline Fontes de variação & Quadrado médio & Coeficiente de variação (\%) \\
\hline Temperatura & $1607,63^{\text {ns }}$ & 3,19 \\
Teor de água & $64614,22^{*}$ & \\
\hline Temperatura x Teor de água & $429,65^{\text {ns }}$ & \\
\hline Fontes de variação & Porosidade & \\
\hline Temperatura & Quadrado médio & 4,44 \\
Teor de água & $23,13^{*}$ & \\
\hline Temperatura x Teor de água & $31,14^{*}$ & \\
\hline
\end{tabular}

${ }^{*}$ Significativo; ${ }^{\text {ns }}$ não significativo em nível de $5 \%$ de probabilidade pelo teste $\mathrm{F}$.

Fonte: Elaboração dos autores.

Com a redução do teor de água ocorreu a redução da massa específica aparente, sendo as reduções de 80,$6 ; 73,0 ; 67,0 ; 70,1$ e $78,8 \mathrm{~kg} \mathrm{~m}^{-3}$ para as temperaturas de $45,60,75,90$ e $105{ }^{\circ} \mathrm{C}$, respectivamente (Figura 3). A redução da massa específica com o processo de secagem vem sendo observada para a maioria dos produtos agrícolas (COUTO et al., 1999; AFONSO JÚNIOR; CORRÊA; ANDRADE, 2000; RIBEIRO et al., 2005; RAZAVI et al., 2007; RESENDE et al., 2008b; SIQUEIRA; RESENDE; CHAVES, 2012b).

Ainda na Figura 3 verifica-se que, a massa específica diminui com a redução do teor de água. Comportamento inverso ao observado por Garnayak et al. (2008), que trabalhando com o método de reumedecimento de sementes encontraram valores de massa específica aparente variando de 492 a 419 $\mathrm{kg} \mathrm{m}^{-3}$, para sementes de pinhão-manso com teor de água entre 4,75 e 19,57 (\% b.u.). Logo é possível afirmar que além do teor de água a massa específica aparente é influenciada pelo processo de adsorção ou dessorção, que consiste em ganho e perda de água, respectivamente (CORRÊA et al., 2006). Essa diferença pode ser decorrência do fenômeno da histerese, uma vez que, a contração dos poros capilares das sementes durante a secagem não acontece na mesma proporção durante a expansão dos mesmos durante o reumedecimento. 
Figura 3. Valores médios da massa específica aparente das sementes de pinhão-manso submetidas à secagem em cinco condições de ar.

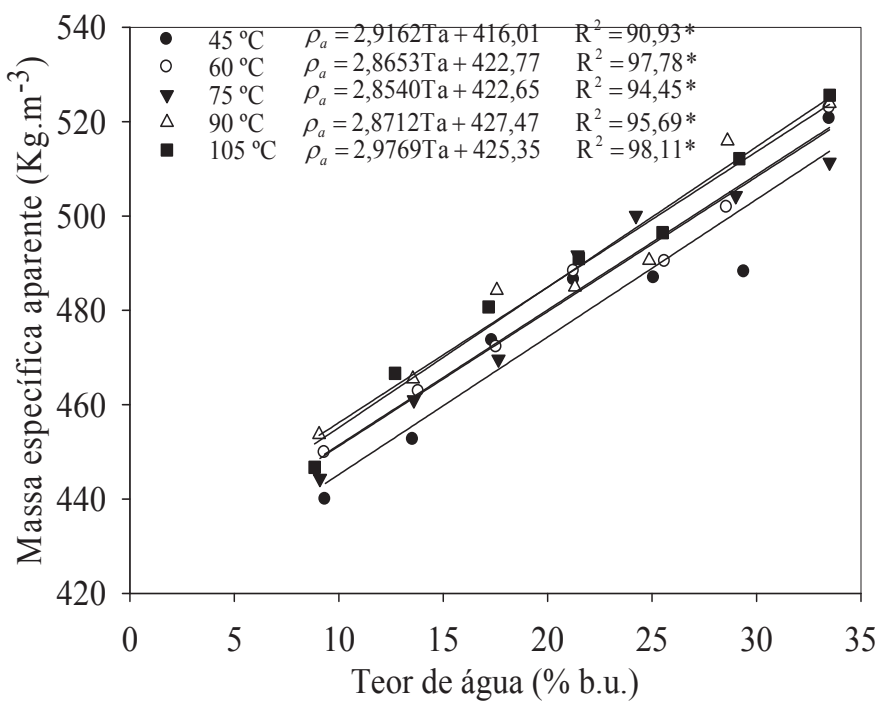

Fonte: Elaboração dos autores.

Com o processo de secagem a massa específica unitária reduziu 209,2; 194,3; 187,9; 189,9 e 198,8 $\mathrm{kg} \mathrm{m}^{-3}$ para as temperaturas de 45, 60, 75, 90 e 105 ${ }^{\circ} \mathrm{C}$, respectivamente (Figura 4). Comportamento semelhante ao observado na massa específica aparente (Figura 3).

Trabalhando com sementes de mamona, espécie da mesma família do pinhão-manso, Goneli (2008) também observou a redução da massa específica unitária ao longo do processo de secagem. O pesquisador destacou que, sementes de mamona apresentam espaços vazios no seu interior e que, a contração volumétrica durante a secagem é pequena, fazendo com que o volume das sementes permaneça praticamente constante, enquanto ocorre redução de sua massa durante a secagem. Esses resultados evidenciam que o encolhimento das sementes de mamona e pinhão-manso não acompanha a redução de suas massas com a secagem. Isso pode estar relacionado às características de rigidez apresentada pelo tegumento das sementes dessas espécies. Resultados semelhantes foram observados para sementes de feijão (RESENDE et al., 2008b), de castanhas e pistache (RAZAVI et al., 2007), grãos de soja (RIBEIRO et al., 2005), grãos de arroz em casca (REDDY; CHAKRAVERTY, 2004), sementes de abóbora (PAKSOY; AYDIN, 2004), de café com pergaminho (PÉREZ-ALEGRÍA; CIRO; ABUD, 2001; CHANDRASEKAR; VISWANATHAN, 1999) e frutos de café (COUTO et al., 1999).

Nota-se ainda nas Figuras 3 e 4 que a variação das massas específicas aparente e unitária em função da redução do teor de água pode ser descrita por meio de modelos lineares, como observado por diversos pesquisadores (DEMIR et al., 2002; BARYEH; MANGOPE, 2002; ABALONE et al., 2004; RIBEIRO et al., 2005; NIMKAR, MANDWE; DUDHE, 2005; RESENDE et al., 2008b; PRADHAN et al., 2009).

Optou-se pela utilização dos valores médios de porosidade, uma vez que, não houve interação entre os fatores temperatura e teor de água e por não ser possível a representação da porosidade em cada condição de secagem por meio de uma equação de regressão. 
Figura 4. Valores médios da massa específica unitária das sementes de pinhão-manso ao longo da secagem em diversas temperaturas.

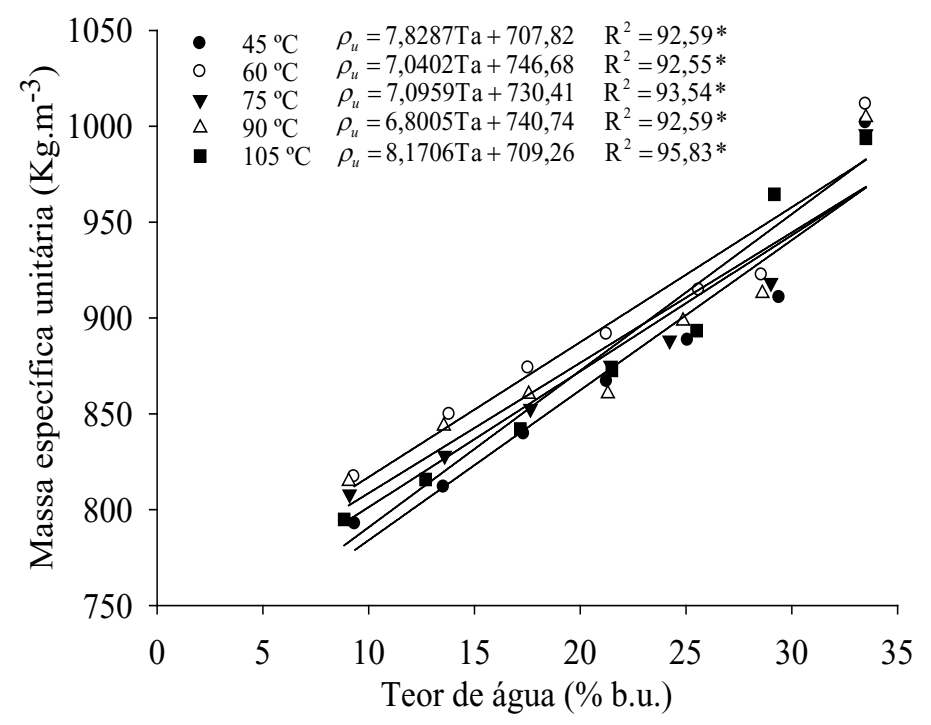

Fonte: Elaboração dos autores.

Figura 5. Valores médios da porosidade das sementes de pinhão-manso submetidos à secagem em cinco condições de temperatura.

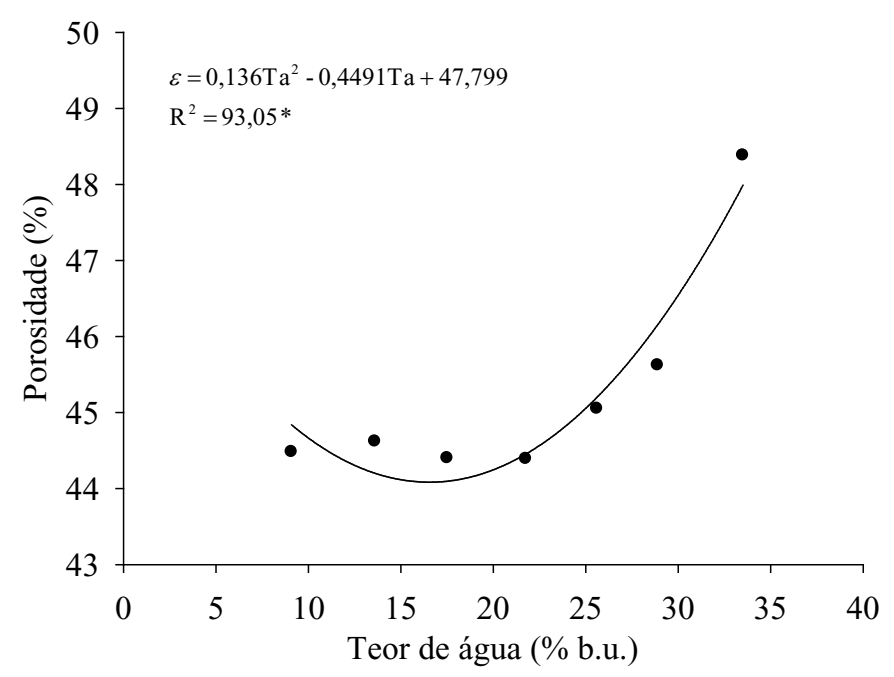

Fonte: Elaboração dos autores.

A porosidade variou de 48,38 a $44,48 \%$, com a redução do teor de água de 33,33 para 9,09 $\pm 0,3$ (\% b.u.) (Figura 5). Estes valores estão próximos aos observados para outros produtos agrícolas: milhopipoca (RUFFATO et al., 1999), café (COUTO et al., 1999), soja (RIBEIRO et al., 2005) e mamona (GONELI, 2008). Os valores médios estão abaixo dos obtidos por Sirisomboon et al. (2007), que trabalhando com sementes de pinhão-manso encontraram uma porosidade de $56,73 \%$ para o 
teor de água de $25,42 \%$ (b.u.). As divergências nos valores de porosidade podem estar relacionadas com a diversidade genética das variedades das sementes e o manejo adotado durante os períodos pré e/ou pós-colheita.

Estudando a porosidade das sementes de pinhãomanso Garnayak et al. (2008), encontraram uma variação de 27,54 a 45,37\% à medida que o teor de água variava de 4,75 para $19,37 \%$ (b.u.). Sirisomboon e Kitchaiya (2009) verificaram que a porosidade das sementes de pinhão-manso foi de 46; 59,31 e $57,93 \%$, quando estas foram submetidas à secagem nas temperaturas de 80,60 e $40^{\circ} \mathrm{C}$, respectivamente. Logo, fica explícita a influência do teor de água sobre a porosidade intergranular de pinhão-manso, pois com o processo de secagem há uma redução na porosidade das sementes. No entanto, assim como os resultados obtidos por Sirisomboon e Kitchaiya (2009), não foi possível observar uma tendência de comportamento da porosidade com o aumento da temperatura de secagem.

Corrêa et al. (2003), trabalhando com grãos de milheto, alpiste e painço também observaram comportamento quadrático para a porosidade destes produtos ao longo do processo de secagem.

\section{Conclusões}

A redução do teor de água causa decréscimo na porosidade e nas massas específicas aparente e unitária das sementes de pinhão-manso. A temperatura do ar de secagem não exerce influência sobre a massa específica unitária das sementes de pinhão-manso.

\section{Referências}

ABALONE, R.; CASSINERA, A.; GASTÓN, A.; LARA, M. A. Some Physical properties of amaranth seeds. Biosystems Engineering, London, v. 89, n. 1, p. 109-117, 2004.

ABDAlla, A. L.; SILVA FILHO, J. C.; GODOI, A. R.; CARMO, C. A.; EDUARDO, J. L. P. Utilização de subprodutos da indústria de biodiesel na alimentação de ruminantes. Revista Brasileira de Zootecnia, Viçosa, MG, v. 37, p. 260-258, 2008. Especial.

AFONSO JÚNIOR, P. C.; CORRÊA, P. C.; ANDRADE, E. T. Análise da variação das propriedades físicas e contração volumétrica dos grãos de milheto (Pennisetum glaucum) durante o processo de dessorção. Revista Brasileira de Armazenamento, Viçosa, v. 25, n. 1, p. 1521, 2000.

ARRUDA, F. P. de; BELTRÃO, N. E. M.; ANDRADE, A. P. de A.; PEREIRA, W. E.; SEVERINO, L. S. Cultivo de pinhão manso (Jatropha curcas L.) como alternativa para o semi-árido nordestino. Revista Brasileira de Oleaginosas e Fibrosas, Campina Grande, v. 8, n. 1, p. 789-799, 2004.

BARYEH, E. A.; MANGOPE, B. K. Some physical properties of QP-38 variety pigeon pea. Journal of Food Engineering, Essex, v. 56, n. 1, p. 59-65, 2002.

BRASIL, Ministério da Agricultura e Reforma Agrária. Secretaria Nacional de defesa Agropecuária. Regras para análise de sementes. Brasília: Mapa/ACS, 2009. 395 p.

CHANDRASEKAR, V.; VISWANATHAN, R. Physical and thermal properties of coffee. Journal of Agricultural Engineering Research, Washington, v. 73, n. 3, p. $227-$ 234, 1999.

CORRÊA, P. C.; AFONSO JÚNIOR, P. C.; ANDRADE, E. T.; SILVA, F. S. Determinação das propriedades físicas da massa granular de milheto, alpiste e painço. Revista Brasileira de Armazenamento, Viçosa, v. 28, n. 2 p. 4650, 2003.

CORRÊA, P. C.; AFONSO JÚNIOR, P. C.; RIBEIRO, D. M.; SILVA, F. S. Equilíbrio higroscópico de milheto, alpiste e painço: obtenção e modelagem. Revista Brasileira de Engenharia Agrícola e Ambiental, Campina Grande, v. 10, n. 1, p. 162-167, 2006.

COUTO, S. M.; MAGAlHÃES, A. C.; QUEIROZ, D. M.; BASTOS, I. T. Massa específica aparente e real e porosidade de grãos de café em função do teor de umidade. Revista Brasileira de Engenharia Agrícola e Ambiental, Campina Grande, v. 3, n. 1, p. 61-68, 1999.

DEMIR, F.; DOĞAN, H.; ÖZCAN, M.; HACISEFEROĞULLARI, H. Nutritional and physical properties of hackberry (Celtis australis L.). Journal of Food Engineering, Essex, v. 54, n. 3, p. 241-247, 2002.

FERREIRA, D. F. SISVAR: um programa para análises estatísticas e ensino de estatística. Revista Symposium, Lavras, v. 6, n. 2, p. 36-41, 2008.

GARNAYAK, D. K.; PRADHAN, R. C.; NAIK, S. N.; BHATNAGAR, N. Moisture-dependent physical properties of Jatropha seed (Jatropha curcas L.). 
Industrial Crops and Products, Amsterdam, v. 27, n. 1, p. 123-129, 2008.

GONELI, A. L. D. Variação das propriedades físicomecânicas e da qualidade de mamona (Ricinus communis L.) durante a secagem e o armazenamento. 2008. Tese (Doutorado em Engenharia Agrícola) - Universidade Federal de Viçosa, Viçosa, MG.

GONELI, A. L. D.; CORRÊA, P. C.; MAGALHÃES, F. E. A.; BAPTESTINI, F. M. Contração volumétrica e forma dos frutos de mamona durante a secagem. Acta Scientiarum. Agronomy, Maringá, v. 33, n. 1, p. 1-8, 2011.

LAHSASNI, S.; KOUHILA, M.; MAHROUZ, M.; JAOUHARI, J. T. Drying kinetics of prickly pear fruit (Opuntia ficus indica). Journal of Food Engineering, Essex, v. 2, n. 61, p. 173-179, 2004.

MELO, E. C.; LOPES, D. C.; CORRÊA, P. C. GrapsiPrograma computacional para o cálculo das propriedades psicrométricas do ar. Engenharia na Agricultura, Viçosa, v. 12, n. 2, p. 154-162, 2004.

MOHAPATRA, D.; RAO, P. S. A thin layer drying model of parboiled wheat. Journal of Food Engineering, Essex, v. 66, n. 4 , p. 513-518, 2005.

MOHSENIN, N. N. Physical properties of plant and animal materials. New York: Gordon and Breach Publishers, 1986. $841 \mathrm{p}$.

NIMKAR, P. M.; MANDWE, D. S.; DUDHE, R. M. Physical properties of moth gram. Biosystems Engineering, London, v. 91, n. 2, p. 183-189, 2005.

PAKSOY, M.; AYDIN, C. Some physical properties of edible squash (Cucurbita pepo L.) seeds. Journal of Food Engineering, Essex, v. 65, n. 2, p. 225-231, 2004.

PÉREZ-ALEGRÍA, L. R.; CIRO, V. H. J.; ABUD, L. C. Physical and termal properties of parchment coffee bean. Transactions of the ASAE, Saint Joseph, v. 44, n. 6, p. 1721-1726, 2001.

PRADHAN, R. C.; NAIK, S. N.; BHATNAGAR, N.; VIJAY, V. K. Moisture-dependent physical properties of jatropha fruit. Industrial Crops and Products, Amsterdam, v. 29, n. 2-3, p. 341-347, 2009.

RAZAVI, S. M. A.; RAFE, A.; MOGHADDAM, T. M.; AMINI, A. M. The physical properties of pistachio nut and kernel as a function of moisture content and variety: part II. Gravimetrical properties. Journal of Food Engineering, Essex, v. 81, n. 1, p. 218-225, 2007.

REDDY, B. S.; CHAKRAVERTY, A. Physical properties of raw and parboiled paddy. Biosystems Engineering, London, v. 88, n. 4, p. 461-466, 2004.
RESENDE, O.; ARCANJO, R. V.; SIQUEIRA, V. C.; RODRIGUES, S. Modelagem matemática para a secagem de clones de café (Coffea canephora Pierre) em terreiro de concreto. Acta Scientiarum. Agronomy, Maringá, v. 31, n. 2, p. 189-196, 2009.

RESENDE, O.; CORRÊA, P. C.; GONELI, A. L. D.; RIBEIRO, D. M. Propriedades físicas do feijão durante a secagem: determinação e modelagem. Ciência $e$ Agrotecnologia, Lavras, v. 32, n. 1, p. 225-230, 2008 b.

RESENDE, O.; CORRÊA, P. C.; GONELI, A. L. D.; BOTELHO, F. M.; RODRIGUES, S. Modelagem matemática do processo de secagem de duas variedades de feijão (Phaseolus vulgaris L.). Revista Brasileira de Produtos Agroindustriais, Campina Grande, v. 10, n. 1, p. 17-26, 2008a.

RESENDE, O.; CORRÊA, P. C.; GONELI, A. L. D.; CECON, P. R. Forma, tamanho e contração volumétrica do feijão (Phaseolus vulgaris L.) Durante a secagem. Revista Brasileira de Produtos Agroindustriais, Campina Grande, v. 7, n. 1, p. 15-24, 2005.

RIBEIRO, D. M.; CORRÊA, P. C.; RODRIGUES, D. H.; GONELI, A. L. D. Análise da variação das propriedades físicas dos grãos de soja durante o processo de secagem. Ciência e Tecnologia de Alimentos, Campinas, v. 25, v. 3 , p. 611-617, 2005.

RUFFATO, S.; CORRÊA, P. C.; MARTINS, J. H.; MANTOVANI, B. H. M.; SILVA, J. N. Influência do processo de secagem sobre a massa específica aparente, massa específica unitária e porosidade de milho-pipoca. Revista Brasileira de Engenharia Agrícola e Ambiental, Campina Grande, v. 3, n. 1, p. 45-48, 1999.

SANTOS, S. B.; MARTINS, M. A.; CARVALHO, F. M.; CARNEIRO, A. C. O. Determinação de algumas propriedades físicas dos grãos de pinhão-manso (Jatropha curcas L.). In: DI LEO, N.; MONTICO, S.; NARDÓN, G. Avances en ingeniería rural: 2007 - 2009. Rosario: UNR Editora, 2009. p. 1067-1072.

SATURNINO, H. M.; KAKIDA, D. D. P. J.; TOMINAGA, N.; GONÇALVES, N. P. Cultura do pinhão-manso (Jatropha curcas L.). Informe Agropecuário, Belo Horizonte, v. 26, n. 229, p. 44-78, 2005.

SILVA, J. S. Secagem e armazenagem de produtos agrícolas. Viçosa: Aprenda Fácil, 2008. 559 p.

SIQUEIRA, V. C.; RESENDE, O.; CHAVES, T. H. Determination of the volumetric shrinkage in jatropha seeds during drying. Acta Scientiarum. Agronomy, Maringá, v. 34, n. 3, p. 231-238, 2012a. 
Propriedades físicas dos frutos de pinhão-manso durante a secagem. Global Science and Technology, Rio Verde, v. 5, n. 1, p. 83-92, 2012 b.

SIRISOMBOON, P.; KITCHAIYA, P. Physical properties of Jatropha curcas L. kernels after heat treatments. Biosystems engineering, London, v. 102, n. 2, p. 244250, 2009.

SIRISOMBOON, P.; KITCHAIYA, P.; PHOLPHO, T.; MAHUTTANYAVANITCH, W. Physical and mechanical properties of Jatropha curcas L. fruits, nuts and kernels. Biosystems Engineering, London, v. 97, n. 2, p. 201-207, 2007.
SOUZA, A. D. V.; FÁVARO, S. P.; ÍTAVO, L. C. V.; ROSCOE, R. Caracterização química de sementes e tortas de pinhão-manso, nabo-forrageiro e crambe. Pesquisa Agropecuária Brasileira, Brasília, v. 44, n. 10, p. 1328-1335, 2009.

ULLMANN, R.; RESENDE, O.; SALES, J. F.; CHAVES, T. H. Qualidade das sementes de pinhão manso submetidas à secagem artificial. Revista Ciência Agronômica, Fortaleza, v. 41, n. 3, p. 442-447, 2010. 